\title{
Editorial Family Violence and its Elimination: The Search for New Ways
}

\author{
Rachael Sanders and Jennifer Lehmann \\ Co-Editors, Children Australia
}

As a significant social problem at the foreground of social and political commentary violence, and violence against women (VAW) in particular, is receiving a great deal of local and global attention (Hooker, Kaspiew, \& Taft, 2016). Following years of campaigning by women's groups, there appears to be substantial will and determination to redress this social problem both here and abroad. The movement started back in the late 1960s, with Scotland being one of the countries that led the way and 'Much of this work was undertaken by women's units, equalities units, and later, community safety units.' Various efforts were made to address violence towards women and sexual abuse; and 'Undoubtedly the most high profile example of this was the development in 1992/1993 of the Zero Tolerance poster campaign by Edinburgh District Council Women's Unit' (The Scottish Government, 2005).

While the extent of the problem is not completely known, there is no doubt that the prevalence of violence is unacceptably high (World Health Organization (WHO), 2010). For too long VAW was hidden behind closed doors and treated as a personal trouble, but the feminist movement of the 1970s altered this attitude and, more recently, the doors have been flung open to expose VAW as a public issue and related to social structures (Murray \& Powell, 2009). Accordingly, the United Nations has issued a global call to action to end VAW (WHO, 2013).

According to the latest Australian Personal Safety Survey, $41 \%$ of all women and over $49 \%$ of all men have experienced at least one incident of violence since the age of 15 (ABS, 2012). The main difference between female and male experiences of violence is that women are much more likely to be assaulted by a partner or ex-partner and be the victim of family and domestic violence (FDV). Over a quarter of Australian women have experienced intimate partner violence in their lifetime (Cox, 2015; Rees et al., 2014; Taft, Watson, \& Lee, 2004), and that rate is much higher for
Indigenous women (Berry, Harrison, \& Ryan, 2009) with $24 \%$ having experienced such abuse in the 12 months prior to being surveyed (Al-Yaman, Van Doeland, \& Wallis, 2006).

Women's experiences and responses to violence differ, but it is thought to have wide-reaching negative consequences. Violence has been implicated in problems to do with mental health (mainly depression), sleeplessness, homelessness, higher rates of pregnancy termination, lowered self-esteem, increased engagement in high risk behaviours and suicidal ideation (Astbury, Bruck, \& Loxton, 2011; Australian Human Rights Commission, 2015; Australian Institute of Health and Welfare (AIHW), 2015; Delfabbro et al., 2006; Senior \& Chenhall, 2012; Taft \& Watson, 2007, 2008). Moreover, DFV can negatively impact on experiences of motherhood and ability to parent effectively which, in turn, can impact on childhood attachment and developmental outcomes (Hooker et al., 2016; WHO, 2010). For example, a study in Victoria estimates that among women 18-44 years of age, intimate partner violence was associated with $7 \%$ of the overall burden of disease, which was a larger risk factor than some of the more familiar contributors such as raised blood pressure, smoking and increased body weight (Vos et al., 2006).

In their recent scoping review, Hooker, Anderson, Theobald, Billet, and Baron (in review) suggest there is much more to learn and do to overcome this problem. One of the dominant views amongst scholars is that genderbased cultural beliefs and practices are at the root of the problem. For example, male-governed hierarchies can add to the legitimisation of dominance by men in political, organisational, community and family contexts, and the construction of the romantic storyline as a dominant discourse of femininity has been implicated in the defence or excuse for violent behaviour - 'it's because he loves me so much!' (Baker, 2003). Key to ameliorating VAW, therefore, will be 
addressing attitudes towards VAW and the broader community and organisational cultures and structures responsible for shaping them (Wall, 2014). While preventions and interventions that target particular groups and communities are imperative, prevention of VAW is more likely to be achieved when these are complemented by universal approaches. Whole-of-population activities that address inequitable gendered attitudes and standards are likely to temper negative consequences of gender imbalance that perpetuate VAW.

This sort of broad cultural shift is one of the key recommendations made in the recent Victorian Royal Commission into Family Violence (2016). The Report appeals for community effort to help shape attitudes and define what is acceptable and unacceptable. The commissioner calls on workplaces, sporting clubs, faith communities and other social networks to be places that 'combat violence supporting attitudes and promote respectful relationships' (Neave, Faulkner, \& Nicholson, 2016, p. 14). A suite of primary prevention strategies that are aimed at reaching the broader Victorian community, as well as initiatives targeted at specific groups, are recommended. For example, healthy relationship training in schools as a way of transforming cultural norms and developing positive attitudes for and within future generations is encouraged. While the Report encourages education in schools about DFV and the broader issue of gender equality and respectful relationships, it is important that this does not occur as a program specific conversation, but that it permeates everyday activities, conversations and practice examples. For example, it is important to ask if there is a relatively equal balance between female and male staff in management positions in schools; whether the arts and sports are given equal priority and importance in achievements; and if staff are modelling female empowerment and gender respect and equality within the school culture.

While the factors that contribute to DFV in Australia, like in other countries, are a complex mesh of interacting elements, it is also useful to think of the macro, mezzo and micro features that we might be able to affect for the better. One of the noticeable features at the micro level is the lack of interest in promoting and talking opening about feminist principles and values by younger women or perhaps it is a lack of identification with, and articulation of, the core principles that is the issue. The gains made by women through the 1960s, 1970s and 1980s seem to have slipped from the regard of younger women, particularly in more conservative communities. For example, in discussions with social work students in regional Australia there is a worrying lack of concern about the position of women in society and a tendency to see issues mostly in terms of how they might affect an individual. This is surprising given the amount of time spent alerting students to the systemic issues in society that lead to poverty or homelessness, for instance. However, it is as though if an attitude of "I am OK" predominates, then little attention is given to women's rights and equity issues at the mezzo and macro levels. One young woman recently commented that if she voiced comments that suggested a feminist orientation she would have no friends and be set aside by her peer group. Another women of mature age responded to a question about feminism with the remark that she had no interest in the "burning of bras and that stuff" and it had no place in her life. What was remarkable about this was that the same woman had battled to attain rights to services for herself and her family, and had much to say about systems in society that afforded women and their children little regard. However, this was not identified as forming the basis for support of women's rights or feminism.

The sense of connection to feminism might be lacking, but with the current focus on promoting rights to safety and nonviolence towards women, it is surprising that more women are not demonstrating concern about the strong gendering taking place in the commercial world and at a political-macro-level. The lack of women in leadership roles in commercial, government and political contexts continues to be an area of concern as is the financial wellbeing of women in retirement, the ongoing expectations of women to provide the major part of domestic and care duties, and the lack of equity in pay between men and women. In addition, we seem to have lost the challenge to the gendering of toys and clothes, to the use of public spaces, and to the objectification of women as sexual objects.

At the mezzo level, groups of women do come together in various causes, such as Grandmothers Against Children in Detention (n.d.), but these efforts appear to be largely cause-based rather than reflecting wider challenges to gendered behaviours that discriminate against women and their wellbeing. This is leading to an action-oriented response that needs to be linked to the broader demands for systemic change based on what are essentially feminist principles.

In spite of the many thrusts to promote women's issues across the world, it is clear many women have felt unable to challenge the behaviour of male partners that has resulted in our current concerns about family violence, though in Australia Rosie Batty and her colleagues are continuing to lead the way in changing this. Sadly, she has been labelled a "left feminist" by people who are threatened by the effectiveness of her work. For example, Latham (2016) is quoted as stating: "You would find by attacking poverty rather than attacking men you'll get a far better solution than the nonsense we're hearing from Rosie Batty and the other left feminists." The debate has been reported by News.com.au with this passage taken from an online article addressing feminism in Australia at the present time:

'... the term 'feminist' is bandied about as a well-worn insult across opinion pages and talk back radio.

In recent years, the stigma attached to feminism seems to have sharpened as the women's movement got swept up in an increasingly bitter and partisan political environment.

Women advocating for gender equality on the public stage are frequently now not labelled feminists, but 'lefty-feminists', raising doubts about whether it is even possible to be of a 
conservative political persuasion and still identify as feminist. (Anon, 2016)

At the macro level feminism in Australia has become caught in party politics and this is not to the advantage of women, young or older, in this country. In Australia, we have a long way to go to both understand and resolve the tensions associated gender relationships, but in the meantime we have a tendency to go for the negative and conjure fear of being tagged feminist, rather than seeing the importance of both men and women taking a closer look at the benefits of behaving in a principled and equitable manner to reduce the discrimination women experience at micro, mezzo and macro levels.

While large formal programmes are likely to have an effect, one wonders to what extent small individual changes can impact upon societal attitudes. For example, everyday language may have the potential to undermine equality when is it "normal" to put men before women in everyday expressions such as "Mr and Mrs" or "boys and girls". Examples of this are rife in contemporary popular culture. Reality television home improvement programs provide an example in which couples are typically introduced with the man preceding the woman or, even more insidiously, with the man followed by the woman who is defined as the wife of the husband-"this is Jack and his wife, Jill". In addition, men are typically portrayed as the leaders of family projects and events even when couples work in partnership.

Without deliberate reflection these language norms creep into our daily lives without conscious thought, but they can be easily challenged. As a way of promoting the imbalance of gender status that appears to be entrenched in our gendered society we could each think about the times in our work and daily living that we can reverse the norm and put women before men. For instance, research staff could report female statistics before male statistics. In organising children's sporting activities girls could be promoted as umpires of football matches and boys as umpires of netball games. Real-estate agents could shake a women's hand before a man's. Banks and other organisations could address letters to Mrs and $\mathrm{Mr}$ Smith. These may seem trivial and an insignificant drop in a very big ocean, but when combined each drop may form small waves of social consciousness that together create a tsunami of gender equality that ultimately change the landscape of social inequalities and injustices that ultimately contribute to VAW. This is a strategy known as gender mainstreaming and is a key initiative of institutional promotion of gender equality at the organisational level. Gender mainstreaming requires reconsideration of concepts and processes that are gendered, but also allows for gender differences to be valued (Walby, 2005). It is often the case that when broad cultural changes are the recommended remedy we look to governments or organisations to lead the way, but equally it can be argued that individuals hold the power to change, create and perpetuate cultural norms and values, even if it is only one drop at a time. The question is, how many drops can we each contribute and how can we mobilise others to make their contribution?

The first three articles in this issue address various matters to do with child protection. Having identified minimal research on the decision-making processes involved in removing a child from parental care, Karen Broadley has developed twelve decision-making criteria to assist practitioners when making these decisions. These criteria take into account the nature of abuse/neglect, statutory requirements, and characteristics of the child, perpetrator and other caregivers. The application of these decision-making criteria, according to Karen, will improve consistency in outcomes for children and families.

The second paper examines the experiences of grandparents whose contact with their grandchildren is lost or reduced as a result of a child's involvement with child protection services. In-depth interviews with grandparents emphasised the important relationship between grandparents and grandchildren and highlighted the difficulties that many grandparents faced when trying to maintain contact. In this paper, Erin Rigby, Susan Gair and Ros Thorpe identify ways that workers can promote these relationships for the wellbeing of both grandparents and children.

Examining issues to do with child protection from the worker's perspective, Carolyn Cousins has written a thought-provoking commentary on the potential challenges faced by child protection workers who become parents during their time of employment. She points to the necessity of critical reflection in every day practice to identify where the personal and the professional intersect, with particular reference to transference and countertransference. Carolyn explores this topic by drawing on her experiences as a parent and clinical supervisor. She identifies the need for more research to examine the impact that becoming a parent can have on workers and their clients.

Jenni Southwell evaluates the yourtown's Expressive Therapies Intervention which involve creative arts and play therapies that aid in the treatment of children experiencing emotional and behavioural problems resulting from early trauma. She found that the intervention can contribute to positive outcomes for preschool-aged children with participants' social, emotional and behavioural functioning improving from intake to exit. Children's self-confidence, self-esteem and the quality of the parent-child attachment relationship were all found to be significantly improved post intervention.

A systematic review of literature to do with the health and wellbeing of young children across the transition to school by Jennifer Fane, Colin MacDougall, Gerry Redmond, Jessie Jovanovic and Paul Ward, identified seven main themes: current conceptualisations of health and wellbeing, assessment and measurement, 'school readiness', service integration, transition actors, 'at risk' children and child voice. The findings indicate a lack of cohesion across the health and education sectors with regard to research, policy and practice 
during children's transition to school. The authors highlight key questions for future research, with a particular focus on positioning children as active participants in childhood research. Moreover, it highlights that 'what is known' can be used to inform the review or implementation of services, practices and partnerships that support child health and wellbeing during the transition to school.

The penultimate paper examines the experiences of young Australian families with parents on military deployment. Adding to the limited, but growing literature and research on the topic of defence force issues, Marg Baber identifies some of the key ways that parents help their families cope with the stressors related to military deployment.

The final paper, by Helen Hickson, Jennifer Lehmann and Fiona Gardner consider the ways in which reflection and reflective practice are shaped during the early years. The study they conducted found that early experiences of storytelling, and encouragement to reflect on behaviours, contributes to later capacities for reflective practice. Acknowledging that not all people have such opportunities through their childhood and adolescent years, they suggest that children exposed to disadvantage and trauma are engaged in conversations that encourage the deconstruction of assumptions and explore multiple perspectives as integral to their care. This provides them with a chance to develop the reflective capacities needed to develop new perspectives and resilience.

This issue concludes with a book review by Frank Ainsworth of the somewhat controversial book written by Jeremy Sammut entitled The madness of Australian child protection. Why adoption will rescue Australia's underclass of children.

\section{References}

Al-Yaman, F., Van Doeland, M., \& Wallis, M. (2006). Family violence among Aboriginal and torres strait islander peoples. Australia: AIHW.

Anon, (March 8. 2016). Inside Australian's ongoing gender wars and how the meaning of feminism has changed. News.com.au. Retrieved from http://www.news. com.au/lifestyle/inside-australians-ongoing-gender-warsand-how-the-meaning-of-feminism-has-changed/newsstory/f0df2f580d51075bd6935cea63de929b.

Astbury, J., Bruck, D., \& Loxton, D. (2011). Forced sex: A critical factor in the sleep difficulties of young Australian women. Violence and Victims, 26(1), 53-72.

Australian Bureau of Statistics. (2012). Personal Safety, Australia, 2012. Cat No. 4906.0. Retrieved from http:// www.abs.gov.au/ausstats/abs@.nsf/Lookup/4906.0Chapter 2002012.

Australian Institute of Health and Welfare. (2015). Specialist homelessness services 2014-15. Retrieved from http://www. aihw.gov.au/homelessness/specialist-homelessnessservices-2014-15/.

Australian Human Rights Commission. (2015). Children's Rights Report 2015. Sydney, NSW. Retrieved from https:// www.humanrights.gov.au/our-work/childrens-rights/ publications/childrens-rights-report-2015.

Baker, J. (2003). Don't believe the hype: Young women's experience of male violence in the 'girl power' era. Women Against Violence: An Australian Feminist Journal, 14, 27-34.

Berry, J. G., Harrison, J. E., \& Ryan, P. (2009). Hospital admissions of Indigenous and non-Indigenous Australians due to interpersonal violence, July 1999 to June 2004. Australian \& New Zealand Journal of Public Health, 33(3), 215-222. doi: 10.1111/j.1753-6405.2009.00378.x.

Cox, P. (2015). Violence against women in Australia: Additional analysis of the Australian Bureau of Statistics' Personal Safety Survey, 2012. Australia's National Research Organisation for Women's Safety (ANROWS) Horizons Research Report.

Delfabbro, P., Winefield, T., Trainor, S., Dollard, M., Anderson, S., Metzer, J., \& Hammarstrom, A. (2006). Peer and teacher bullying/victimization of South Australian secondary school students: Prevalence and psychosocial profiles. British Journal of Educational Psychology, 76(1), 71-90.

Grandmothers Against Detention of Refugee Children (n.d.). Retrieved from https://www.facebook.com/ Grandmothers-against-Detention-of-Refugee-ChildrenMelbourne-Ports-1535108210063047/.

Hooker, L., Anderson, K., Theobald, J., Billet, P., \& Baron, P. (in review). Violence against young rural women in Australia: A scoping review.

Hooker, L., Kaspiew, R., \& Taft, A. (2016). Domestic and family violence and parenting: Mixed methods insights into impact and support needs: State of knowledge paper. Sydney: ANROWS. Retrieved from http://media.aomx. com/anrows.org.au/s3fs-public/L1.16_1.8\%20Parenting. pdf.

Latham, M. (2016). Mark Latham slams Rosie Batty's 'feminist nonsense' in podcast spray. 7 News. Retrieved from https:// au.news.yahoo.com/a/30631549/mark-latham-slams-rosie -battys-feminist-nonsense-in-podcast-spray/.

Murray, S., \& Powell, A. (2009). "What's the problem?" Australian public policy contrstuctions of domestic and family violence. Violence Agaisnt Women, 15(5), 532-552.

Neave, M., Faulkner, P., \& Nicholson, T. (2016). Royal commission into family violence: Summary and recommendations. Melbourne: Victorian governemnt.

Rees, S., Steel, Z., Creamer, M., Teesson, M., Bryant, R., McFarlane, A. C., ... Silove, D. (2014). Onset of common mental disorders and suicidal behavior following women's first exposure to gender based violence: A retrospective, population-based study. BMC Psychiatry, 14, 312. doi: http://dx.doi.org/10.1186/s12888-014-0312-x.

Senior, K. A., \& Chenhall, R. D. (2012). Boyfriends, babies and basketball: Present lives and future aspirations of young women in a remote Australian Aboriginal community. Journal of Youth Studies, 15(3), 369-388. doi: http://dx.doi.org/10.1080/13676261.2012.663890.

Taft, A. J., \& Watson, L. F. (2007). Termination of pregnancy: Associations with partner violence and other factors in a national cohort of young Australian women. Australian and New Zealand Journal of Public Health, 31(2), 135-142. doi:10.1111/j.1753-6405.2007.00031.x. 
Taft, A. J., \& Watson, L. F. (2008). Depression and termination of pregnancy (induced abortion) in a national cohort of young Australian women: The confounding effect of women's experience of violence. BMC Public Health, 8, 75. doi: http://dx.doi.org/10.1186/1471-2458-8-75.

Taft, A. J., Watson, L. F., \& Lee, C. (2004). Violence against young Australian women and association with reproductive events: A cross-sectional analysis of a national population sample. Australian \& New Zealand Journal of Public Health, 28(4), 324-329.

The Scottish Government. (2005). Violence against Women: A literature review commissioned by the National Group to Address Violence Against Women. Retrieved from http://www.gov.scot/Publications/2005/03/20895/55137.

Vos, T., Astbury, J., Piers, L. S., Magnus, A., Heenan, M., Stanley, L., ... Webster, K. (2006). Measuring the impact of intimate partner violence on the health of women in Vic- toria, Australia. Bulletin of the World Health Organization, 84(9),739-744.

Walby, S. (2005). Gender mainstreaming: Productive tensions in theory and practice. Social Politics, 12(3), 3213-3243.

Wall, L. (2014). Gender equality and violence against women: What's the connection? (ACSSA Research Summary). Melbourne: Australian Centre for the Study of Sexual Assault, Australian Institute of Family Studies.

World Health Organization. (2010). Preventing intimate partner and sexual violence against women: Taking action and generating evidence. Geneva: World Health Organization.

World Health Organization. (2013). Global and regional estimates of violence against women: Prevalence and health effects of intimate partner violence and non partner sexual violence. Geneva. Retrieved from http://apps.who. int/iris/bitstream/10665/85239/1/9789241564625_eng.pdf. 